\title{
Content and Mobility Behavior of Iron and Manganese in Asphaltite Burning Residue Using ICP-OES
}

\author{
Isil Aydin a*, Beniz Gunduz ${ }^{\mathrm{b}}$, Firat Aydin ${ }^{\mathrm{c}}$, Osman Akba ${ }^{\mathrm{c}}$, Abdurrahman Saydut ${ }^{\mathrm{d}}$, and Candan Hamamci ${ }^{\mathrm{c}}$ \\ a Dicle University, Pharmacy Faculty, Analytical Chemistry Department, Diyarbakur, Turkey \\ ${ }^{b}$ Selcuk University, Science Faculty, Chemistry Department, Konya, Turkey \\ ${ }^{\mathrm{c}}$ Dicle University, Science Faculty, Chemistry Department, Diyarbakır, Turkey \\ ${ }^{d}$ Dicle University, Engineering Faculty, Mining Engineering Department, Diyarbakir, Turkey
}

\section{INTRODUCTION}

Fuel combustion products are one of the more important anthropogenic sources of emission of many metals and metalloids into the environment (1-5). In the burning process of fuel, minerals undergo thermal decomposition, fusion, disintegration, and agglomeration $(6,7)$. The elements associated with sulfide minerals and organic matter are more volatile compared to those in different chemical forms, like oxides (8). The conventional method for identification and evaluation of the availability of heavy metals in ash samples is carried out by leaching of the samples via chemical extractants. Both single extraction and sequential extraction have been used (9-11). In this case, the most important information is the metal content, the chemical species, and the condition of metal migration from the studied material into the environment (12-14).

Asphaltites are formed by migration and later solidification of petroleum. The inorganic residue derived from the burning of asphaltite represents the noncombustible impurities originally present in asphaltite. Mineral matter is a complex mixture of inorganic minerals and elements except for carbon, hydrogen, oxygen, nitrogen, and sulphur (15-18). Chemical speciation of $\mathrm{Fe}$ and $\mathrm{Mn}$ is necessary for risk assessment of asphaltite burning residue (ABR). $\mathrm{Mn}$ is considered to be characteristic of fossil fuels from various sources $(19,20)$. Among the heavy metals

*Corresponding autbor.

E-mail: iaydin@dicle.edu.tr

\section{ABSTRACT}

The determination of inorganic pollutants leaching from solid waste, such as coal, asphaltite, oil shale, and ash, is an important topic for industrial applications and solid waste management. This study presents the concentration and fractionation of iron ( $\mathrm{Fe}$ ) and manganese (Mn) in asphaltite burning residue (ABR) and their determination by inductively coupled plasma optical emission spectrometry (ICP-OES). A modified Tessier sequential extraction method was used for the fractionation of Fe and $\mathrm{Mn}$ in four forms (exchangeable, carbonates, bound to organic and sulfide, and residual content). Investigations on the $\mathrm{Fe}$ and $\mathrm{Mn}$ chemical fractions and their environmental mobility in ash solution systems were carried out. It was found that $\mathrm{Mn}$ in $\mathrm{ABR}$ (from Harbul-Silopi, Turkey) occurs in the following fractions: exchangeable (13.56\%), associated with carbonates (28.94\%), associated with organic matter and sulfides (17.48\%), and residual content ( $40.08 \%)$. Fe occurs in the following fractions: exchangeable (11.11\%), carbonates $(27.68 \%)$, organic matter and sulfides (23.39\%), and residual content (37.82\%). Among these fractions, the exchangeable and carbonate-bound fractions are unstable and prone to leach out, while the organic matter-bound fractions and the residual fractions are considered to be relatively stable and of low bioavailability. Thw mobility fractions of Fe contain 38.79\% and of Mn contain $42.50 \%$ of their total concentration in ABR under normal environmental conditions. found in the environment, Mn presents one of the most insidious and widespread health hazards. Mn is an essential trace element known to be related particularly to the reproductive functions. Its deficiency may lead to negative effects such as brain damage, teratogenicity, skeletal abnormalities, and abnormal metabolism of lipids and carbohydrates. Miners exposed to chronic manganese overload show symptoms of the extrapyramidol system, surprisingly similar to those of patients with Parkinson's disease. For this reason, Mn can become a highly toxic heavy metal, emitted from industrial sources, which can seriously damage human health. It can also affect the ecosystem negatively, accumulating in the food chain $(20,21)$. Different veins of asphaltic materials have different physical and chemical characteristics depending on the location of the asphaltic material, geological formation, and degree of metamorphosis (22). The Harbul vein (in Silopi, SE Anatolia, Turkey) is the major source for asphaltites used by power plants in the production of electrical energy (23). Environmental contamination caused by the disposal of asphaltite burning residue, and also by other industrial applications, requires knowledge of their total metal concentrations in addition to the available metal fraction to other environmental components. The total metals concentration applied for environmental evaluations leads to an over-estimation of the contamination once it is well known that a significant fraction of the metals is immobilized in the solid matrix. In a natural environment, leaching of pollutants from an ash matrix is carried out by chelating agents in the form of 
humic acids $(24,25)$. The structure of these complexes is affected significantly by the solubility and mobility of the metals in solid waste (26).

In the present study, the modified Tessier sequential extraction method (27) was applied for the determination of binding forms of iron and manganese in the asphaltite burning residue (ABR) and for evaluation of their leaching behavior in view of their potential environmental impact. The elemental determinations in the different leachates were performed by inductively coupled plasma optical emission spectrometry (ICP-OES).

\section{EXPERIMENTAL}

\section{Instrumentation}

A PerkinElmer Optima ${ }^{\mathrm{TM}} 2100$ DV inductively coupled plasma optical emission spectrometer (ICPOES) (PerkinElmer, Inc., Shelton, CT, USA) was used for the determination of Fe and $\mathrm{Mn}$ in asphaltite burning residue (ABR). The ICPOES operating conditions are listed in Table I. All of the procedures from sampling to analysis were also applied to the blanks in order to evaluate any metal contamination during the analytical procedure. A blank was simultaneously prepared and all procedures were applied before measurements.
Selection of the instrumental parameters and the optical wavelengths was based on obtaining good sensitivity, reasonable detection limits, and eliminating interferences (2). Internal standards were not used for this study. The direct calibration process was performed for Mn and Fe, and the respective calibration curve for each metal is shown in Figure 1 ( $a$ and $b$ ).

\section{Reagents}

The reagents used were of Suprapur ${ }^{\circledR}$ grade (Merck \& Co., Darmstadt, Germany) or of analytical grade and used without further purification. Deionized water, obtained with a Milli-Q ${ }^{\circledR}$ system (Millipore Corporation, Bedford, MA, USA), was used throughout this study.

TABLE I

ICP-OES Operating Conditions of the PerkinElmer Optima 2100 DV

$\begin{array}{ll}\text { Parameters } & \\ \text { RF power } & 1450 \mathrm{~W} \\ \text { Plasma gas flow rate } & 15 \mathrm{~L} \mathrm{~min}^{-1} \\ \text { Auxiliary gas flow rate } & 0.2 \mathrm{~L} \mathrm{~min}^{-1} \\ \text { Nebulizer gas flow rate } & 0.8 \mathrm{~L} \mathrm{~min}^{-1} \\ \text { Sample flow rate } & 1.5 \mathrm{~L} \mathrm{~min}^{-1} \\ \text { View mode } & \text { Axial } \\ \text { Read } & \text { Peak area } \\ \text { Source equilibration time } & 15 \mathrm{~s} \\ \text { Read delay } & 50 \mathrm{~s} \\ \text { Replicates } & 3 \\ \text { Background correction } & 2 \text {-point (manual point correction) } \\ \text { Spray chamber } & \text { Scott type spray chamber } \\ \text { Nebulizer } & \text { Cross-Flow GemTip } \\ & \text { (HF resistant) } \\ \text { Detector } & \text { CCD } \\ \text { Purge gas } & \text { Nitrogen } \\ \text { Shear gas } & \text { Air } \\ \text { Gas } & \text { Argon } \\ \text { Analytical wavelengths } & \text { Fe 238.204 nm, Mn 257.610 nm } \\ \end{array}$

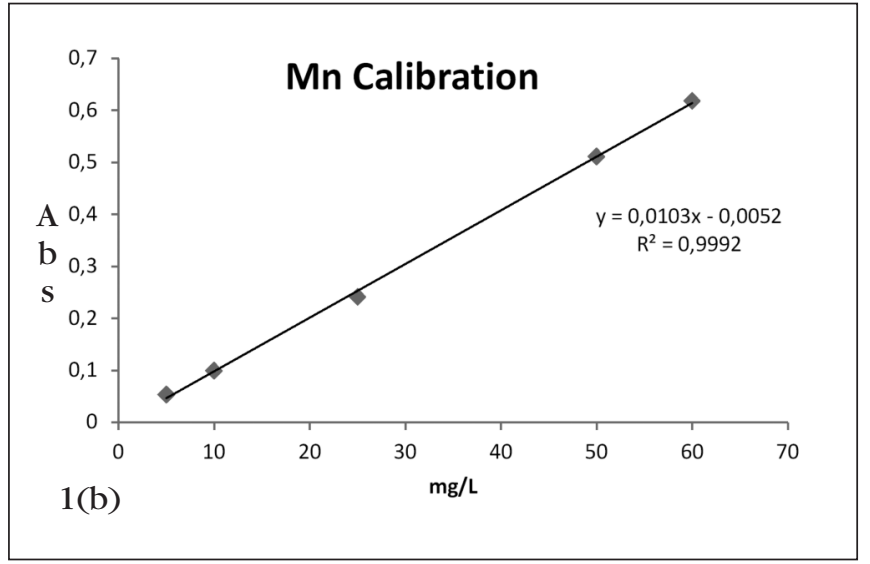

Fig. 1 ( $a$ and $b$ ). Calibration curve of Fe and Mn. 


\section{Sample Preparation}

The asphaltite sample was obtained in lump form from the Harbul (Silopi) asphaltite field (Harbul vein $2.5^{\circ} 10^{7}$ tonnes), located in the SE Anatolia region of Turkey. A sample amount of about $20.0 \mathrm{~g}$ was oven-dried with a Memmert ULM 500 drying oven (Germany) at $105^{\circ} \mathrm{C}$, crushed with a Retsch BB1/A jaw breaker (Germany), and ground in a Retsch SRZ rotor beater mill. The particle sizes of the samples were sifted to less than $300 \mu \mathrm{m}$. The heating value and the ash and sulfur concentrations of the samples were determined according to ASTM procedures (22). For analysis, $20.0 \mathrm{~g}$ of asphaltite was weighed into a porcelain crucible and subjected to the calcination step in a muffle furnace at $950{ }^{\circ} \mathrm{C}$ for about 6 hours.

\section{Digestion Procedure}

A Berghof MWS-3 microwave digestion system (Berghof, USA) was used for acid digestion of the asphaltite burning residue. The two-stage, five-step microwave acid digestion was applied. An amount of $0.3 \mathrm{~g}$ dried ABR sample was weighed and transferred into a pressure-resistant polytetrafluoroethylene (PTFE) vessel and an acid mixture of $10 \mathrm{~mL} \mathrm{HNO}_{3}+3 \mathrm{~mL} \mathrm{HF}$ added $(5,8)$. The vessel was then sealed and mounted in a sleeve for one hour, then removed and cooled to room temperature in a waterbath. The method and acid composition of the first step were the same as used for the one-stage digestion, except for the digestion program. An amount of $20 \mathrm{~mL}$ of $\mathrm{H}_{3} \mathrm{BO}_{3}$ was added to the sample, the vessel returned to the microwave digestion system, and the second stage applied using the conditions listed in Table II at $1000 \mathrm{~W}$ power. The reaction mixture was subjected to an evaporation module in order to remove the acids after the final digestion $(11,14)$. Then the residue was dissolved in Milli- $\mathrm{Q}^{\mathrm{TM}}$ water, filtered, and the filtrate diluted to a fixed volume of $50 \mathrm{~mL}$.

\section{Modified Tessier Sequential Extraction Procedure}

The modified Tessier sequential extraction procedure was used to study the iron and manganese distribution in the Silopi asphaltite burning residue $(3,20,27)$. The

TABLE II

Operating Conditions for the Two-Stage Microwave Digestion

\begin{tabular}{lrrr}
\hline Step 1 & & & \\
\hline $\mathrm{T}^{\mathrm{o}} \mathrm{C}$ & 140 & 160 & 190 \\
Ta (min) & 5 & 5 & 3 \\
Time (min) & 5 & 10 & 20 \\
\hline Step 2 & & & \\
$\mathrm{T}^{\mathrm{o}} \mathrm{C}$ & 160 & 100 \\
$\mathrm{Ta}\left(\right.$ min $^{\mathrm{a}}$ & 3 & 2 \\
Time (min) & 15 & 15 \\
\hline
\end{tabular}

${ }^{a}$ Waiting time at desired temperature.

b The time between the two successive temperatures.

\section{Atomic Spectroscopy \\ 1 Vol. 35(6), Nov./Dec. 2014}

operating conditions of the method are listed in Table III.

\section{Fraction 1 - Exchangeable}

Approximately $1 \mathrm{~g}$ asphaltite burning residue was extracted with $10 \mathrm{~mL}$ of $1 \mathrm{M}$ ammonium acetate $(\mathrm{pH}=7)$. After 1 hour of shaking at $200 \mathrm{rpm}$ at room temperature, the sample was centrifuged for $10 \mathrm{~min}$ utes at $5000 \mathrm{rpm}$. The liquid phase was decanted and diluted to $50 \mathrm{~mL}$ with ultrapure water.

\section{Fraction 2 - Carbonate}

To the residue of fraction 1 , $10 \mathrm{~mL}$ of $1 \mathrm{M}$ acetic acid was added $(\mathrm{pH}=5)$. After 1 hour of shaking at $200 \mathrm{rpm}$, it was centrifuged for 10 minutes at $5000 \mathrm{rpm}$ at room temperature. The liquid phase was decanted and diluted to $50 \mathrm{~mL}$ with ultrapure water.

\section{Fraction 3 -Bound to Organic and Sulfide}

The residue from fraction 2 was treated with $5 \mathrm{~mL}$ of a $30 \%$ solution of $\mathrm{H}_{2} \mathrm{O}_{2}(\mathrm{pH}=2$ with $\mathrm{HNO}_{3}$ ) and shaken at $35^{\circ} \mathrm{C}$ and $200 \mathrm{rpm}$ for 3 hours. After centrifugation at 10,000 rpm, the samples were paper-filtered and diluted to $100 \mathrm{~mL}$ with ultrapure water.

\section{Fraction 4 - Residual Content}

A mixture of aqua regia $\left(\mathrm{HCl} / \mathrm{HNO}_{3}, 3: 1\right)$ was added to the filtered residue from fraction 3 . After microwave destruction, the samples were paper filtered and diluted to $100 \mathrm{~mL}$ with ultrapure water.

TABLE III

Operating Conditions Required for the Modified Tessier Sequential Extraction Method

\begin{tabular}{clll}
\hline Fraction & Nominal Fraction & Extractant & Extraction Conditions \\
\hline 1 & Exchangeable & $1 \mathrm{M}$ ammonium acetate $(\mathrm{pH}=7)$ & Shaken $1 \mathrm{~h}, 25^{\circ} \mathrm{C}$ \\
2 & Carbonates & $1 \mathrm{M}$ acetic acid $(\mathrm{pH}=5)$ & Shaken $1 \mathrm{~h}, 25^{\circ} \mathrm{C}$ \\
3 & Bound to organic and sulfide & $30 \%$ solution of $\mathrm{H}_{2} \mathrm{O}_{2}\left(\mathrm{pH}=2\right.$ with $\left.\mathrm{HNO}_{3}\right)$ & Shaken $3 \mathrm{~h}, 35^{\circ} \mathrm{C}$ \\
4 & Residual content & $\mathrm{HCl}^{\circ} \mathrm{HNO}_{3}(3: 1)$ & Acid digestion \\
\hline
\end{tabular}




\section{Accuracy of the Analytical Method}

The certified reference material (CRM) NIST-1633b Coal Fly Ash (National Institute of Standards and Technology, Gaithersburg, MD, USA) was used to check the accuracy of the analytical method used. The results are listed in Table IV.

\section{RESULTS AND DISCUSSION}

This study presents the concentration and fractionation of $\mathrm{Fe}$ and $\mathrm{Mn}$ in the inorganic residue derived from the burning of asphaltite and represents its noncombustible impurities. Table $\mathrm{V}$ lists the elemental analysis of the studied asphaltite. The reagents used in the various stages of analysis selectively leach certain fractions of the ABR.

Microwave-acid digestion (MW$\mathrm{AD}$ ), followed by inductively coupled plasma optical emission spectrometry (ICP-OES), was examined for the determination of total Fe and Mn. Dry ashing was used for the almost complete elimination of the organic materials prior to analyte determination. The burning temperature of $950{ }^{\circ} \mathrm{C}$ was found to be the best as a result of the trade-off between the overall iron and manganese recovery yield (10). In this research, wet acid digestion ( $\mathrm{HCl}, \mathrm{HNO}_{3}, \mathrm{H}_{3} \mathrm{BO}_{3}$ ) was used for the $\mathrm{Fe}$ and Mn determinations. Crystallization of $\mathrm{CaF}_{2}$ was avoided by the addition of boric acid. The two-stage, five-step microwave digestion method was carried out as detailed above in Table II.

It can be seen that the proposed ICP-OES procedure is the most simple and reliable analytical method for the elemental analysis of asphaltite burning residue due to its high selectivity and low interference problems. ICP-OES functions best when the samples are in the aqueous or solution phase. The total Fe and Mn concentrations
TABLE IV

Accuracy Assessment Through the Analysis of CRM NIST-1633b Constituent Elements in Coal Fly Ash

\begin{tabular}{lcc}
\hline Element & Certified & Found \\
\hline Fe $($ wt \%) & $7.78 \pm 0.23$ & 8.01 \\
$M n\left(\mathrm{mg} \mathrm{kg}^{-1}\right)$ & $131.8 \pm 1.7$ & $130.7 \pm 2.4$ \\
\hline
\end{tabular}

found in the Silopi ABR were $5.13 \mathrm{wt}^{2} \%$ and $55.73 \mathrm{mg} \mathrm{kg}^{-1}$, respectively.

Although assessment of the total concentration of Fe and $\mathrm{Mn}$ is still useful in many areas, knowledge of their speciation is of primary importance because their characteristic toxicity, mobility, bioavailability, and bioaccumulation depends on their different chemical fractions. Fractionation of Fe and Mn was carried out using the modified Tessier method based on the sequential extractions of the metals from the ABR, each releasing four forms of Fe and Mn: exchangeable (fraction 1), carbonates (fraction 2), bound to organic and sulfide (fraction 3), and residual fraction (fraction 4).

As can be seen in Table VI, the most abundant fraction of both $\mathrm{Fe}$ and $\mathrm{Mn}$ in ABR was in the residual fraction (fraction 4). The presence of $\mathrm{Fe}$ and $\mathrm{Mn}$ in the residual fraction is safer for the environment since it shows lowest possible mobility and bioavailability. The most abundant Fe fraction in the carbonates (fraction 2) was second, while in the organic matter and sul-
TABLE V

Elemental and Proximate Analy-

\begin{tabular}{lr}
\hline Elemental Analysis & \multicolumn{1}{c}{$\begin{array}{c}\text { Weight } \\
(\%)\end{array}$} \\
\hline Carbon & 54.079 \\
Nitrogen & 0.764 \\
Hydrogen & 5.122 \\
\hline Proximate Analysis & \\
\hline Moisture & 0.630 \\
Ash & 32.490 \\
Fixed Carbon & 20.140 \\
Volatile matter & 46.740 \\
Heating value $\left(\mathrm{kcal} \mathrm{g}^{-1}\right)$ & 6276.253 \\
\hline
\end{tabular}

fide fraction (fraction 3), it was third. On the other hand, the prevailing $\mathrm{Mn}$ in the carbonate fraction was second, and in the organic matter and sulfides fraction it was third. The values for Fe and Mn were lowest in the exchangeable fraction (fraction 1).

The exchangeable fraction is the most dangerous for the environment. This fraction shows that the amount of Fe and Mn that could be released into the environment sis of Harbul-Silopi Asphaltites

TABLE VI

Concentration of Total and Fractions of Fe and Mn in Asphaltite Burning Residue (ABR)

\begin{tabular}{lrccr}
\hline & Mn $\left(\mathrm{mg} / \mathrm{kg}^{-1}\right)$ & $\mathrm{Mn}(\%)$ & $\mathrm{Fe}(\mathrm{wt} \%)$ & $\mathrm{Fe}(\%)$ \\
\hline Total & $55.73 \pm 1.14$ & 100.00 & $5.13 \pm 0.29$ & 100.00 \\
Exchangeable Fraction & $7.56 \pm 0.42$ & 13.56 & $0.57 \pm 0.05$ & 11.11 \\
Carbonate Fraction & $16.13 \pm 0.24$ & 28.94 & $1.42 \pm 0.12$ & 27.68 \\
$\begin{array}{l}\text { Organic Matter and } \\
\text { Sulfide Fraction }\end{array}$ & $9.74 \pm 0.58$ & 17.48 & $1.20 \pm 0.07$ & 23.39 \\
Residual & $22.34 \pm 0.97$ & 40.08 & $1.94 \pm 0.15$ & 37.82 \\
\hline
\end{tabular}


would increase if the environmental conditions became more acidic $(10,28)$. The carbonate fraction also has an adverse impact on the environment, and under low $\mathrm{pH}$ conditions, Fe and Mn may be present as co-precipitates with carbonate minerals and strongly adsorbed metal forms on the ash surface. Fe and $\mathrm{Mn}$ in this fraction can be released easily by ion exchange processes and can also leach very easily when the environmental conditions become disturbed due to a change in $\mathrm{pH}$ (13).

The metals Fe and $\mathrm{Mn}$ in the exchangeable (fraction 1) and carbonate fractions (fraction 2) play a very important role in the evaluation of the environment and always act as a pollution indicator due to the metals' environmental mobility and bioavailability. The first fraction in ABR is the most labile form that can be easily leached into the environment when the ABR is rinsed by rain or other water bodies. Thus, it can be stated that this fraction is the most active part in nature which poses an environmental risk to human beings and all biological species $(29,30)$.

Fortunately, the amount and proportion of $\mathrm{Fe}$ and $\mathrm{Mn}$ in $\mathrm{ABR}$ that is bound to the organic and sulfide fraction (fraction 3) is low, which is consistent with its chemistry of being predominantly bound as sulfides that do not dissolve in the ABR at this stage. Sulfide solid phases are dissolved in various extraction fractions along the extraction sequence and not only in the "sulfide" fraction. This fraction shows the amount of Fe and Mn bound to the organic matter and sulfur which would be released into the environment if the conditions became oxidative. Most metals readily form compounds with sulfur. The sulfur-binding fraction is normally stable with respect to temperature and lower $\mathrm{pH}$. Fe and $\mathrm{Mn}$ in this fraction are more stable and will take part in the geochemical cycle less easily. Yet, they will become labile when the redox conditions change. Under oxidizing conditions, the organic materials and reducing sulfur compounds may be destroyed, and the metals associated with them can be leached into the environmental water system. The percentage of total Fe and Mn leached from the organic matter and sulfide fraction (fraction 3) was $23.39 \%$ and $17.48 \%$, respectively.

\section{Results of Using Modified Tessier Sequential Method in Residual Fraction}

The strongest affinity of Fe and Mn was found in the residual fraction (fraction 4). The metals were held in a more stable fraction in which the movement of these heavy metals in the ABR profile would be negligible (31). The residual fraction represents the part of Fe and Mn that has strongest association with the crystalline structures of the minerals. However, it is not always easy to extract metals in this fraction. A much higher percentage of metals was noticed in the residual fraction using the modified Tessier scheme (28). The percentages of $\mathrm{Fe}$ and $\mathrm{Mn}$ in the residual fraction $(37.82 \%$ and $40.08 \%$ of the total metal leached) were higher than in the other fractions. The mobilization of elements from the ashes is a relatively slow process, and an equilibrium between the solid and liquid phases may not be attained even after long leaching times. However, short-term leaching experiments are capable of giving critical information in considerably shorter interaction periods.

The results presented in this research imply that the modified Tessier sequential extraction method can be used to identify qualitative differences in the partitioning of Fe and $\mathrm{Mn}$ in the ABR samples collected from the Harbul vein, Silopi, Turkey. The sequential

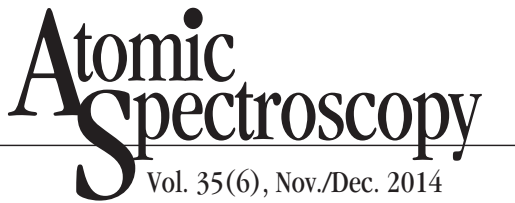

extraction scheme recommended by the modified Tessier method is sufficiently repeatable and reproducible for application in fractionation studies. The advantages of the technique include a high degree of automation, good reproducibility, and short analysis time, which makes it the method of choice for the fractionation of $\mathrm{Fe}$ and $\mathrm{Mn}$ $(10,30,31)$.

Quantitative evaluation of leachable Fe and Mn from ABR to surface waters under environmental conditions, in addition to metal contamination of the environment, is essential. Mn, which is mobile in environmental conditions $(\mathrm{pH}=5-7)$, is associated with the exchangeable fraction $(\mathrm{pH}=7)$ and also with the carbonate fraction. The other Mn fractions present in the residue are bound to mobile fractions and can migrate to the environment under specific conditions, i.e., aggressive environments and/or the presence of microorganisms (13).

This study further supports the fact that knowledge of the levels of toxic and potentially toxic elements, especially in the most mobile fractions, is an important tool for environmental risk assessment $(1,10,29,31)$.

\section{CONCLUSION}

This study presents a modified Tessier sequential extraction method for the fractionation of Fe and $\mathrm{Mn}$ from asphaltite burning residue (ABR) in four forms (exchangeable, carbonates, bound to organic and sulfide, and residual content) and their determination by inductively coupled plasma optical emission spectrometry (ICP-OES). The 238.204 $\mathrm{nm}$ and $257.610 \mathrm{~nm}$ lines were used for Fe and Mn determination, respectively.

The proposed method provides quantitative knowledge of the $\mathrm{Fe}$ and $\mathrm{Mn}$ distribution in ABR and 
their toxicity, mobility, leachability, bioaccumulation, and bioavailability. Assessment of the chemical, mineralogical, morphological, and leaching behavior of these ashes is important for their effective management.

The total Fe and Mn concentrations in the ABR (Harbul vein, Silopi, Turkey) were $5.13 \mathrm{wt} \%$ and $55.73 \mathrm{mg} \mathrm{kg}^{-1}$, respectively. This investigation concludes that the most abundant fraction of both $\mathrm{Fe}$ and $\mathrm{Mn}$ in $\mathrm{ABR}$ is in the residual fraction. Relative abundances of the remaining Fe fractions in ash follow the order: Carbonate > Organic matter and sulfur $>$ Exchangeable fraction. The remaining Mn fractions follow the order: Carbonate $>$ Organic matter and sulfur $>$ Exchangeable fraction.

$\overline{\text { Received April 30, } 2014 .}$

\section{REFERENCES}

1. P. Smichowski, G. Polla, D. Gomez, A. J. F. Espinosa, and A. C. Lopez, Fuel 87, 1249 (2008).

2. F. Aydin, A. Saydut, I. Aydin, and C. Hamamci, At. Spectrosc. 32, 194 (2011).

3. A. Saydut, M. Z. Duz, Y. Tonbul, A. Baysal, and C. Hamamci, J. Anal. Appl. Pyrol. 81, 95 (2008).

4. R. Świetlik, M. Trojanowska, and M. A. Jóźwiak, Fuel Process. Technol. 95, 109 (2012).

5. F. Aydin, A. Saydut, B. Gunduz, I. Aydin, S. Erdogan, and C. Hamamci, Energ. Source, Part A, 35, 2356 (2013).

6. R.C. Bhangare, P.Y. Ajmal, S.K. Sahu, G.G. Pandit, and V.D. Puranik, Int. J. Coal Geol. 86, 349 (2011).

7. Y. Tonbul, A. Saydut, and C. Hamamci, Oil Shale 23, 286 (2006).

8. I. Aydin, F. Aydin, E. Kilinc, M. Z. Duz, and C. Hamamci, Chem. Spec. Bioavailab. 25, 113 (2013).
9. S. J. Huang, C. Y. Chang, D. T. Mui, F. C. Chang, M. Y. Lee, and C. F. Wang, J. Hazard. Mater. 149, 180 (2007).

10. F. Aydin, B. Gunduz, I. Aydin, O. Akba, A. Saydut, and C. Hamamci, At. Spectrosc. 34, 140 (2013).

11. I. Aydin, F. Aydin, and C. Hamamci, Microchem J. 108, 64 (2013).

12. S. Akkus, T. Bal, N. M. Karaaslan, E. Yaman, E. Kilinc, M. Yaman, CleanSoil Air Water 41, 1229 (2013).

13. E. Soco and J. Kalembkiewicz, Fuel 88, 1513 (2009).

14. I. Aydin, F. Aydin, and C. Hamamci, Fuel 95, 481 (2012).

15. N. E. Altun, M. V. Kok, and C. Hicyilmaz, Energy \& Fuels 16, 785 (2002).

16. J. Gulen, I. Doymaz, S. Piksin, and S. Toprak, Energy Sources 27, 1457 (2005).

17. R. Ziyadanogullari and I. Aydin, Separ. Sci. Technol. 39, 3113 (2004).

18. A. Saydut, M. Z. Duz, S. Erdogan, Y. Tonbul, and C. Hamamci, Energ. Source, Part A, 33, 3383 (2011).

19. C. Hamamci, F. Kahraman, and M. Z. Duz, Fuel Process. Technol. 50, 171 (1997).

20. J. Kalembkiewicz, E. Sitarz-Palczak, and L. Zapała, Microchem. J. 90, 37 (2008).

21. B. Isik, C. Hamamci, and R. Isik, Asian J. Chem. 18, 1433 (2006).

22. C. Hamamci, M. Z. Duz, A. Saydut, and M. Merdivan, Oil Shale 20, 161 (2003).

23. A. Saydut, M. Z. Duz, I. Aydin, and C. Hamamci, Energ. Explor. Exploit. 26, 133 (2008).

24. S. Erdogan, M. Merdivan, C. Hamamci, O. Akba, and A. Baysal, Anal. Lett. 37, 2565 (2004)

25. M. Flues, I. M. Sato, M. A.Scapin, M. E. B.Cotrim and I. M. C. Camargo, Fuel 103, 430 (2013).

26. S. Erdogan, M. Z. Duz, M. Merdivan, and C. Hamamci, Energy Sources 27, 423 (2005).

27. A. Tessier, P. G. C. Campbell, and M. Bisson, Anal. Chem. 51, 844 (1979).
28. E. D. v. Hullebusch, S. Utomo, M. H. Zandvoort, and P. N. L. Lens, Talanta 65, 549 (2005).

29. G. J. P. Salazar, M. C. Alfaro-De la Torre, R. N. J. Aguirre, R. BrionesGallardo, C. J.Cedeno, and M. G. A. Penuela, Environ. Earth Sci. 69, 197 (2013).

30. Y. Jun, L. Wen-Bing, K. Qing-Na, W. Yu-Yong, H. Ruo, and S. DongSheng, Fuel. 89, 616 (2010).

31. M. Jalali and N. Hemati, Paddy and Water Environ. 11, 299 (2013). 